EGU21-12354, updated on 28 Jan 2022

https://doi.org/10.5194/egusphere-egu21-12354

EGU General Assembly 2021

(c) Author(s) 2022. This work is distributed under

the Creative Commons Attribution 4.0 License.

\title{
An update to the traditional water mass (trans)formation framework.
}

\begin{abstract}
Aqeel Piracha, Antonio Turiel, Estrella Olmedo, and Marcos Portabella
Institute of Marine Sciences (ICM-CSIC), Physical and Technological Oceanography, Spain (piracha@icm.csic.es)

Traditional estimates of convection/water mass formation at the sea surface rely on measurements of air-sea fluxes of heat and freshwater

(evaporation minus precipitation), that are estimated by combining in-situ data with meteorological modelisation. Satellite-based estimates of ocean convection are thus largely impacted by the relatively high uncertainties and low space-time resolution of those fluxes. However, direct satellite measurements of the ocean surface offer a unique opportunity to study convection (upwelling, downwelling) events with unprecedented spatio-temporal resolution compared to in-situ measurements. In this work, we propose an alternative approach to the traditional framework for estimating ocean convection using satellites. Instead of combining highresolution ocean data of sea surface temperature and salinity with the much less precise, less resolved air-sea interaction data, we estimate the air-sea fluxes by computing the material derivatives (using satellite ocean currents) of the satellite sea surface variables. We therefore obtain estimates at the same resolution of the satellite products, and with much better accuracy than what was estimated before. We present some examples of application in the Atlantic ocean and in the Mediterranean sea. Future directions of this work is the study of the seasonal and interannual variability of ocean convection, and the potential changes on deep convection associated to climate variability at different time scales.
\end{abstract}

